\title{
Essencialidade de plano de manejo para licenciamento ambiental de loteamento em área de proteção ambiental
}

\author{
Management plan essentiality for environmental \\ licensing of land allotment in environmental \\ protection area
}

Esencialidad del plan de manejo para licenciamiento ambiental de asignación de tierras en área de protección ambiental

Alfredo Coimbra Escola Superior do Ministério Público de São Paulo

Valter Foleto Santin Universidade Estadual do Norte do Paraná

Resumo Este trabalho trata da necessidade de plano de manejo para licenciamento ambiental de loteamento em área de proteção ambiental. A pretensão é a verificação da importância do plano de manejo para o licenciamento pelo Poder Público, em face da legislação federal aplicável, providência essencial para a regularidade formal do empreendimento. Adotou-se o método hipotético-dedutivo, por meio de pesquisa bibliográfica.

Palavras-chave: Meio ambiente. Licenciamento ambiental. Plano De MANEJO. ÁREA DE PROTEÇÃO AMBIENTAL.

Abstract This work addresses the need for a management plan for environmental licensing of allotment in an environmental protection area. The pretension is the verification of the importance of the manage- 
ment plan for the licensing by the Public Power, in view of the applicable federal legislation, an essential provision for the formal regularity of the enterprise. The hypothetical-deductive method was adopted, through bibliographic research

Keywords: Environment. Environmental licensing. Management PLAN. ENVIRONMENTAL PROTECTION AREA.

Resumen El trabajo trata de la necesidad de plan de manejo para licenciamiento ambiental de loteo en área de protección ambiental. La pretensión es la verificación de la importancia del plan de manejo para el licenciamiento por el Poder Público, frente a la legislación federal aplicable, providencia esencial para la regularidad formal del emprendimiento. Se adoptó el método hipotético-deductivo, por medio de investigación bibliográfica.

Palabras clave: Medio ambiente. Licencias ambientales. Plan de maNEJo. ÁreA DE PROTECCIÓN AMBIENTAL.

\section{INTRODUÇÃo}

O meio ambiente tem provocado alterações socioambientais e normativas diante da necessidade da sua preservação para as gerações futuras, por interesse transgeracional, com reflexo na formulação e execução de políticas públicas de preservação e alcance do chamado desenvolvimento sustentável, inerente ao momento histórico e social.

A sociedade exige do poder público ações e medidas eficientes para conservação da natureza e proteção ambiental, transformando o tema ambiental em assunto essencial de política pública e tema político e social perene.

Nessa linha, uma medida importante de regulamentação do uso do solo de forma sustentável é o mecanismo de licenciamento ambiental, previsto expressamente na Lei 9.985/2000, indispensável para empreendimento em área de proteção ambiental, protegida em stricto sensu, dependente de plano de manejo da área para verificação de adaptação ambiental e ao desenvolvimento sustentável. 
O interesse jurídico e socioambiental é a análise dos instrumentos jurídicos necessários para autorização de implantação de empreendimento sustentável e de acordo com as exigências de preservação ambiental, sendo a pesquisa voltada para aferição da necessidade e obrigatoriedade de apresentação de plano de manejo para instruir o processo de licenciamento ambiental e permitir a autorização para loteamento de imóvel em área de proteção ambiental.

O trabalho adotou o método hipotético-dedutivo, com cotejamento de obras jurídicas de autores brasileiros, por meio da pesquisa bibliográfica em livros e periódicos.

\section{Licenciamento ambiental E Plano de MANEJo PARA IN- TERVENÇÃO EM ÁREA DE PROTEÇÃO AMBIENTAL}

A busca de melhor proteção ambiental passa pelo processo de licenciamento ambiental para a implantação de loteamento de imóvel em área de preservação ambiental, dependente de plano ou projeto de manejo, em unidades de conservação típicas, documento essencial para permitir a autorização e aprovação do loteamento pelo município, que deve ser registrado em 180 dias para o início da realização das obras, necessitando de revalidação caso não formalizado o registro temporâneo, em consonância com o princípio da legalidade.

O plano de manejo, para estudo de impacto socioambiental em projeto de loteamento que tem incidência naquelas áreas, traz elementos para a restrição administrativa de uso do solo, no exercício do poder de polícia ou restrição administrativa.

A própria licença para construir tem prazo de vigência para início da edificação licenciada, em direito adquirido de execução da obra durante o prazo de validade, sem a continuidade do direito se não iniciada a obra e sem ressalva de lei nova (SILVA, 2008, p. 302-303). Não há direito adquirido a construir com base em lei revogada ou decreto de aprovação caduco, sob pena de atingir o interesse geral da comunidade que não pode ser malferido pela vontade particular, ensejando que o 
interesse deste sobrepuje o interesse público, o que é absolutamente defeso (SILVA, 2008, p. 290).

É assente que ninguém adquire direitos contra o interesse público, a prevalecer sobre o interesse privado, com poder da Administração Pública de impedir a continuidade de atividades ou obras particulares licenciadas ou que possam prejudicar o interesse coletivo (MEIRELLES, 1994, passim).

Nessa linha, "o ato de aprovação, pelo chefe do Poder Executivo Municipal, de pedido de parcelamento de solo urbano para fins de loteamento, não materializa ato jurídico perfeito, pois o ato administrativo 'aprovação' tem natureza discricionária e precária, podendo ser revisto pela Administração a qualquer tempo, quando não materializado 0 ato que se pretendia efetuar" (STJ, REsp n $\mathbf{n}^{\mathbf{0}}$. 1.131.588 - GO, Relator: Ministro Luis Felipe Salomão).

Não se pode olvidar, ainda, que o decreto de aprovação de um loteamento é um ato vinculado, porque atrelada a anuência administrativa a normas de regência, previamente estabelecidas, razão por que ele pode ser anulado, quando permeado de ilegalidade.

As atitudes e reações da Administração são tradicionais em relação aos seus próprios atos em caso de vícios ou defeitos substanciais, de revogar, modificar ou rever o ato, de maneira que Themistocles Brandão Cavalcanti preconiza que "todo ato administrativo é assim, por sua natureza, revogável, desde que se verifique qualquer vício que atinja o ato em seus elementos intrínsecos ou extrínsecos" (CAVALCANTI, 1964, p. 284-285).

Isso constitui o chamado princípio da autotutela administrativa, em que a Administração Pública tem o poder-dever de controlar seus próprios atos, revendo-os e anulando-os em caso de alguma ilegalidade, em conformidade com o princípio da legalidade administrativa, por ação da Administração Pública somente dentro da legalidade, obrigando a rever e anular os atos administrativos ilegais, na própria busca da supremacia do interesse público sobre o interesse privado.

A supremacia do interesse consiste em princípio geral de direito, com o prevalecimento do interesse público sobre o privado, com per- 
missão de limitação administrativa em várias atividades, inclusive no uso de propriedade, com obrigação de não fazer (REMEDIO, 2015, p. 91-92 e 641-642).

Se a municipalidade permitir parcelamentos irregulares, sem a fiscalização de órgão ambiental competente nem a exigência de Plano de Manejo de APA, para aqueles espaços de proteção stricto sensu, haverá descumprimento do artigo $27, \S 3^{\circ}$., da Lei n. 9.985/2000 e consequente nulidade do ato administrativo, por ferimento ao princípio da legalidade. A conduta deve ser de evitar atividades antrópicas em área de proteção ambiental sem as formalidades legais, em especial plano de manejo com aptidão para autorizar licenciamento de uso do espaço territorial protegido.

Cabe anotar que plano de manejo é instrumento jurídico diverso de plano local de gestão urbana. A norma legal define plano de manejo como um "documento técnico mediante o qual, com fundamento nos objetivos gerais de uma unidade de conservação, se estabelece o seu zoneamento e as normas que devem presidir o uso da área e o manejo dos recursos naturais, inclusive a implantação das estruturas físicas necessárias à gestão da unidade" (art. 2. XVII, da Lei 9.985) (BRASIL, 2000), num processo de planejamento integrado e participativo. O objetivo é de preservação da qualidade ambiental da APA e sua harmonização com atividades de desenvolvimento social e econômico, em bases sustentáveis, com medidas de promoção e proteção da biodiversidade e integrando a unidade à vida econômica e social das comunidades vizinhas, em desenvolvimento sustentável. Por sua vez, o chamado Plano Local de Gestão Urbana tem característica de instrumento de planejamento, na fixação de diretrizes e orientação de programas, projetos e ações governamentais ou privada, na Área de Proteção Ambiental.

Sobre o plano de manejo, entende Édis Milaré que a lei lhe atribui "ações ou cometimentos de grande alcance, revestindo-o, por assim dizer, de um duplo caráter: preventivo e normativo". Enfatiza que a necessidade de um plano de manejo para cada unidade de conservação, o qual "deverá ser elaborado pelo órgão gestor ou pelo proprietário quando for o caso, no prazo de cinco anos a partir da data de sua cria- 
ção, e abrangerá a área da unidade de conservação, sua zona de amortecimento e os corredores ecológicos, incluindo medidas com o fim de promover sua integração à vida econômica e social das comunidades vizinhas", com "ampla participação da população residente" (MILARÉ, 2015, p. 1.291).

Inegavelmente, o plano de manejo constitui instrumento fundamental de planejamento e de gestão ambiental de uma unidade de conservação, para determinação de zoneamento ambiental e de espaços territoriais especialmente protegidos, em convergência de dois instrumentos da Política Nacional do Meio Ambiente. O plano de manejo expressa o zoneamento ambiental da unidade de conservação, do zoneamento ambiental. A própria lei é específica na obrigação de elaboração de plano de manejo para unidades de conservação, que "devem dispor de um Plano de Manejo" (art. 27, caput, da Lei 9.985/2000), elaborado no prazo de cinco anos a partir de sua criação $\left(\S 3^{\circ}\right.$.).

A propósito, Paulo Affonso Leme Machado aponta o plano de manejo como "a lei interna das unidades de conservação" (2011, p. 918), sendo que as áreas de proteção ambiental são aquelas "de relevante interesse ecológico” pela visão de Luís Paulo Sirvinskas (2018, p. 253).

A ausência de plano de manejo impede a expressão de planejamento e de gestão ambiental, inviabilizando o atingimento dos objetivos pertinentes à criação da unidade de conservação, em atuação funcional limitada, parcial e insuficiente.

Os objetivos de cada unidade de conservação decorrem na Lei 9.985/2000, salientando que os objetivos gerais e objetivos específicos têm importância de efetivação da norma constitucional de proteção especial dos espaços territoriais e seus componentes, para que seja "vedada qualquer utilização que comprometa a integridade dos atributos que justifiquem sua proteção" (art. 225, §1 $1^{\circ}$. III, da Constituição Federal) (BRASIL, 1988).

Leme Machado considera a existência de "um vínculo legal” entre o plano de manejo, a Constituição Federal e a própria Lei 9.985, sem permissão de desatendimento, em obrigatoriedade de presença de matérias em determinados planos de manejo, como "a visitação pública" 
em planos de manejo da Estação Ecológica (art. $9^{\circ}$., §2 $2^{\circ}$ ), do Parque Nacional (art. 11, $2^{\circ}$.), do Refúgio Silvestre (art. 13, §3 ${ }^{\circ}$.), da Reserva Extrativista (art. 18, $\S 3^{\circ}$.), sendo que no plano de manejo da Reserva de Desenvolvimento Sustentável devem ser previstas "as zonas de proteção integral, de uso sustentável e de amortecimento e corredores ecológicos (art. 20, §6 $6^{\circ}$.)" (MACHADO, 2011, p. 916-917).

A preocupação do legislador é tamanha que a norma proíbe expressamente a própria alteração, atividades ou modalidades de utilização em desacordo com os objetivos, plano de manejo e regulamentos das unidades de conservação (art. 28, da Lei n. 9.985/2000) (BRASIL, 2000), com limitações de atividades e obras até a elaboração do plano de manejo, para garantia da integridade dos recursos em proteção e das populações tradicionais residentes para a satisfação de suas necessidades materiais, sociais e culturais (parágrafo único, do art. 28, referido). Isso está em sintonia com o direito ambiental, em especial a defesa do interesse de toda a coletividade, nos termos do artigo 225 da Constituição Federal (BRASIL, 1988), a prevalecer em confronto com interesses particulares, em razão de que o bem jurídico meio ambiente saudável deve prevalecer sobre o interesse patrimonial individual, pela condição de natureza jurídica de direito fundamental e de natureza difusa do meio ambiente.

Paulo de Bessa Antunes salienta que pelo regime constitucional brasileiro o Direito Ambiental é um dos "direitos humanos fundamentais", por consideração do meio ambiente como "um bem de uso comum do povo e essencial à sadia qualidade de vida", considerados de "interesse comum" (ANTUNES, 2001, p. 20).

Nessa toada, a Suprema Corte brasileira tem externado a sua posição de essencialidade de proteção ambiental, sendo acertada a manifestação do ministro Celso de Mello de destacar o próprio direito de "integridade do meio ambiente", por "constituir prerrogativa jurídica de titularidade coletiva, refletindo, dentro do processo de afirmação dos direitos humanos, a expressão significativa de um poder atribuído, não ao indivíduo identificado em sua singularidade, mas num sentido verdadeiramente mais abrangente, à própria coletividade social", considerado como um dos "direitos de terceira geração, que materializam 
poderes de titularidade coletiva atribuídos genericamente a todas as formações sociais", consagrando o princípio da solidariedade e constituem um momento importante no processo de desenvolvimento, expansão e reconhecimento dos direitos humanos, caracterizados, enquanto valores fundamentais indisponíveis, pela nota de uma essencial inexauribilidade" (STF, MS 22.164/SP, Trib. Pleno, Rel. Min. Celso de Mello, j. 30.10.95, DJ 17.11.95, p. 39.206).

O constituinte brasileiro forneceu uma nova dimensão do direito fundamental à vida e do próprio princípio da dignidade da pessoa humana, porque é no meio ambiente o quadro em que se desenvolve a vida humana, com influência nos atributos do direito de propriedade e no próprio direito de construir, para atendimento ao princípio de máxima efetividade de bens ambientais e eficácia da norma constitucional.

Assim, a consagração de um dever jurídico-constitucional de defesa do ambiente vai além da abstenção de comportamentos ecologicamente nocivos, implicando a obrigação de atuar positivamente, obrigação de fazer consistente em impedir atentados ao ambiente ou minimizá-los ao máximo, por força do dever de todos de defesa e preservação do meio ambiente para as presentes e futuras gerações (art. 225, caput, da Constituição Federal) (BRASIL, 1988).

Salienta José Aparecido Gonçalves que a proteção do meio ambiente ecologicamente equilibrado constitui um direito fundamental, "um caráter de direito transindividual, intrageracional e intergeracional", por relação ao "respeito aos interesses que vão além do indivíduo, ultrapassando o limite da esfera de direitos e obrigações de cunho exclusivamente individual, passando a uma dimensão mais nobre, a coletiva" (GONÇALVES, 2014, p. 48).

Nessa ótica, tem atuação o princípio da proibição da proteção deficiente, corolário do princípio da proporcionalidade, em sua feição garantista positiva, voltado a coibir a inércia ou insuficiência da atuação estatal na concretização de direitos fundamentais, em atuação obrigatória do Poder Público para a proteção do bem jurídico.

Também é pertinente a lembrança do princípio da precaução, diante de quadro de que se "a informação científica é insuficiente, incon- 
clusiva e haja indicações de que os possíveis efeitos sobre o ambiente, a saúde das pessoas ou dos animais ou a proteção vegetal possam ser potencialmente perigosos e incompatíveis com o nível de proteção escolhido" (MILARÉ, 2015, p. 264-265), para inibir ou limitar a margem do perigo, de criação possível de danos ambientais, com a restrição mínima de riscos residuais para a população e para o ambiente (MACHADO, 1993, p. 398).

Desse modo, a expansão urbana deve estar em consonância com o plano de manejo para área de proteção ambiental, para preservação de princípios urbanístico-ambientais, mesmo com a existência de múltiplos interesses de origem constitucional a conciliar, como a propriedade, a livre iniciativa, o empreendimento, a qualidade de vida, dentro da realidade do desenvolvimento econômico e social. A conciliação da qualidade ambiental e da boa gestão dos recursos naturais com outros interesses importa na prevalência do meio ambiente, considerado de interesse maior (MILARÉ, 2015, passim).

$\mathrm{O}$ instrumento jurídico preventivo é o licenciamento ambiental, na forma de tutela administrativa preventiva, para evitar danos irreversíveis ao meio ambiente ou mitigar possíveis danos, necessário para a implementação de empreendimentos ou construções.

A sua importância deve ser vista como "uma tentativa de conciliar desenvolvimento econômico e a preservação do meio ambiente, evitando-se, por via de consequência, desperdícios de recursos humanos, físicos e biológicos", conforme apontam José Fernando Vidal de Souza e Erika Von Zuben (2012, p. 39). Eles observam que "com o licenciamento ambiental não se permite que o singelo risco de dano ao meio ambiente seja tratado com condescendência, exigindo-se do poder público a adoção de medidas necessárias e suficientes para evitar sua ocorrência" (SOUZA; ZUBEN, 2012, p. 39).

A jurisprudência tem entendido que pelo princípio da legalidade "é proibido ao órgão ambiental criar direitos de exploração onde a lei previu deveres de preservação" ou falar "em licença ou autorização ambiental tácita", sem direito do ente estatal, em licenciamento ambiental, "dispensar exigências legais, regulamentares ou de pura sabedoria eco- 
lógica, sob pena de, ao assim proceder, fulminar de nulidade absoluta e insanável o ato administrativo praticado, bem como de fazer incidir, pessoalmente, sobre os servidores envolvidos, as sanções da Lei dos Crimes contra o Meio Ambiente (arts. 66, 67 e 69-A) e da Lei da Improbidade Administrativa, às quais se agrega sua responsabilização civil em regime de solidariedade com os autores diretos de eventual dano causado" (STJ, RESP 1.245.149/MS, Rel. Min. Herman Benjamin).

$\mathrm{O}$ eventual uso da terra em discordância com o licenciamento ambiental e o plano de manejo pode gerar obrigação de reparação de dano ambiental, dependendo das variantes verificadas na espécie, se a área é pública ou privada.

Algo de difícil harmonização é a relação entre proteção ambiental e direito de moradia, em área de proteção ambiental, numa situação de irregularidade, ocupação irregular e eventual dano ambiental em área de proteção ambiental.

Ariel Augusto Pinheiro dos Santos e Elcio Nacur Rezende entendem que a "sustentabilidade deve servir como cosmovisão para interpretação do caso concreto", em que a "APA é um instrumento legal que reafirma a necessidade do caráter sustentável dos empreendimentos", devendo ser consideradas "a proteção ambiental e a equidade social", para resposta ao problema, cuja resolução "não deve colocar ninguém em situação de vulnerabilidade social”, em caso de situação de responsabilização e reparação do ambiente da área (SANTOS; REZENDE, 2015 , p. 308-309). Também tem pertinência no debate a própria responsabilidade por omissão do Estado "de implementação de políticas públicas habitacionais possibilitou que os ocupantes adentrassem no imóvel e criassem um dano ambiental na busca de seu direito fundamental" (SANTOS; REZENDE, 2015, p. 309).

A própria busca do cumprimento da função socioambiental da propriedade não é de fácil concreção, incumbindo "buscar formas de dar efetividade às normas existentes", em razão de que o "meio ambiente é essencialmente complexo, e constituído de vários aspectos (naturais, artificiais, culturais e trabalhistas) não sendo possível a sua redução a 
uma equação simples e de fácil resolução" (GONÇALVES; REZENDE, 2013, p. 137).

E ainda é pertinente e imprescindível "diagnóstico socioambiental" para eventual regularização fundiária, na reparação de problemas urbanos, decorrente de ocupações irregulares ou clandestinas, realizadas por famílias de baixa renda, com mecanismos e instrumentos adequados para a efetivação dos princípios da precaução e prevenção, para atender ao meio ambiente ecologicamente equilibrado, em "realidade transindividual", com "a vigilância do Ministério Público, conformando a situação fática às necessidades sociais, urbanísticas e ambientais, atendendo à sua constitucional função", conforme defendem Luiz Fernando Rossetti Borges, Henrique Augusto Reberte e Paulo Antonio Locatelli (2016, p. 50).

Marcelo Antonio Theodoro salienta o amparo do constituinte para a proteção do meio ambiente e de outros interesses difusos e coletivos, por intermédio de ações constitucionais, em especial a ação civil pública e a ação popular, com objetivo de diminuição de "sensação de impotência muitas vezes presentes em grandes ou pequenos desastres ambientais, todos eles de responsabilidade do homem, travestido ora como governo, ora como pessoa jurídica, ou pessoalmente", com a observação de que a reparação civil pode minimizar danos reversíveis (THEODORO, 2016, p. 83-84).

Portanto, para legal e regular intervenção em área de proteção ambiental stricto sensu há necessidade de plano de manejo e licenciamento ambiental, especialmente para implantação de loteamento e moradia, em que é ínsita a geração de resíduos ambientais e de afetação ao meio ambiente especialmente protegido, em evidente conflito à harmonia e equilíbrio para geração de desenvolvimento sustentável, com possibilidade de ingresso de ação civil pública e ação popular em caso de omissão do responsável e do próprio Poder Público, para coibição da irregularidade e da ilicitude. 


\section{Considerações finais}

O plano de manejo, sob o âmbito de uma APA, é documento essencial para licenciamento ambiental e início de atividades em área de proteção ambiental, sendo irregular e ilícita a sua ausência, e adoção de medidas e ações sem o cumprimento de formalidades legais.

A implantação de loteamento em área de proteção ambiental (APA) depende, pois, de prévia autorização administrativa, por licenciamento ambiental, contendo o plano de manejo.

O empreendimento para moradia, em que é ínsita a geração de resíduos ambientais, provoca outros efeitos antrópicos ao meio ambiente, exigindo por isso rigor do poder de polícia estatal, na autorização e fiscalização de intervenção humana, visando a compatibilização entre o uso do solo para moradia e o equilíbrio ambiental, dentro da concepção de desenvolvimento sustentável e defesa ambiental determinados pela Constituição Federal.

A omissão do responsável e do próprio Poder Público pode provocar a necessidade de ação civil pública e ação popular para coibição da irregularidade e ilicitude.

\section{REFERÊNCIAS}

ANTUNES, Paulo de Bessa. Direito ambiental, 5. ed., Rio de Janeiro: Lumens Juris, 2001.

BORGES, Luiz Fernando Rossetti; REBERTE, Henrique Augusto; LOCATELLI, Paulo Antonio. O diagnóstico socioambiental como pressuposto de execução da regularização fundiária em área de preservação permanente: uma análise a partir da atuação do Ministério Público. Revista Jurídica do Escola Superior do Ministério Público de São Paulo (RJESMPSP), São Paulo, v. 9, n. 1, 2016, p. 31-52. Disponível em: http://www.esmp.sp.gov.br/revista_esmp/ index.php/RJESMPSP/article/view/229/156. Acesso em: 10 nov. 2018. 
BRASIL. Constituição da República Federativa do Brasil de 1988. Brasília, Distrito Federal: Senado, 1988. Disponível em: http:/www.planalto.gov. br/ccivil_03/constituicao/constituicao.htm. Acesso em: 15 out. 2018.

. Lei 9.985 de 2000. Regulamenta o art. 225, $\S 1^{\circ}$., incisos I, II, III e VII da Constituição Federal, institui o Sistema Nacional de Unidades de Conservação da Natureza e dá outras providências. Brasília, Distrito Federal: Senado, 2000. Disponível em: http://www.planalto.gov.br/ccivil_03/LEIS/L9985.htm. Acesso em: 15 out. 2018.

CAVAlCANTI, Themistocles Brandão. Tratado de Direito Administrativo, 5 ed., 1964, v. 1.

GONÇALVES, Daniela Oliveira; REZENDE, Elcio Nacur. Função socioambiental da propriedade: a busca por uma determinação pragmática de aferição de cumprimento. Revista Paradigma, Ribeirão Preto-SP, a. XVIII, n. 22, p. 119-140, jan./dez. 2013. Disponível em: http://www9.unaerp.br/revistas/index.php/paradigma/article/view/243/308. Acesso em: 10 nov. 2018.

GONÇALVES, José Aparecido. O dano ambiental e as gerações futuras. Argumenta Journal Law, Jacarezinho - PR, Brasil, n. 21. p. 25-50, 2014. Disponível em: http://seer.uenp.edu.br/index.php/argumenta/article/view/399/ pdf_64. Acesso em: 16 nov. 2018.

MACHADO, Paulo Affonso Leme. Direito Ambiental Brasileiro, 19 ed. São Paulo: Malheiros, 2011.

. Princípios gerais do direito ambiental internacional. In: Antonio Herman V. Benjamin (Coord.). Dano ambiental: prevenção, reparação e repressão. São Paulo: RT, 1993.

MEIRELLES, Hely Lopes. Direito de Construir, 6. ed. São Paulo: Malheiros, 1994.

MILARÉ, Édis. Direito do ambiente, 10. ed. São Paulo: RT, 2015.

REMEDIO, José Antonio. Direito administrativo, 2. ed. São Paulo: Verbatim, 2015.

SANTOS, Ariel Augusto Pinheiro dos; REZENDE, Elcio Nacur. A responsabilidade civil para reparação de danos ambientais ocorridos em área de proteção ambiental e o paradoxo com o direito fundamental à moradia digna. Ca- 
dernos de Direito, Piracicaba, v. 15 (29): 291-311, jul./dez. 2015. Disponível em: https://www.metodista.br/revistas/revistas-unimep/index.php/cd/article/ view/2529/1614. Acesso em: 10 nov. 2018.

SILVA, José Afonso. Direito urbanístico brasileiro. São Paulo: Malheiros, 2008.

SIRVINSKAS, Luís Paulo. Manual de Direito Ambiental, 16. ed. São Paulo: Saraiva, 2018.

SOUZA, José Fernando Vidal de; ZUBEN, Erika von. O Licenciamento Ambiental e a Lei Complementar ${ }^{\circ}$. 140/2011. Cadernos de Direito, Piracicaba, v. 12 (23): 11-44, jul./dez. 2012. Disponível em: https://www.metodista. $\mathrm{br} /$ revistas/revistas-unimep/index.php/cd/article/view/1594/1022. Acesso em 8 nov. 2018.

THEODORO, Marcelo Antonio. Tutela processual do meio ambiente no Brasil. Revista de Direito Ambiental e Socioambientalismo. Conselho Nacional de Pesquisa e Pós-graduação em Direito (CONPEDI), Florianópolis, v. 2, n. 2, p. 68-85, jul./dez. 2016. Disponível em: http://indexlaw.org/index.php/Socioambientalismo/article/view/1616/2086. Acesso em: 11 nov. 2018.

\section{DAdos dos AUtores}

\section{Alfredo Coimbra}

Especialista em Direito pela Escola Superior do Ministério Público de São Paulo. Promotor de Justiça. E-mail: alfredo-coimbra@hotmail.com

\section{Valter Foleto Santin}

Professor dos programas de Mestrado e Doutorado da Universidade Estadual do Norte do Paraná (UENP, Campus Jacarezinho, Brasil), Doutor em Direito (USP - Universidade de São Paulo, Brasil), Pós-doutor pelo programa do Ius Gentium Conimbrigae (Coimbra, Portugal). Líder do Grupo de pesquisa Políticas públicas e efetivação dos direitos sociais (UENP). Promotor de Justiça. E-mail: valtersantin@apmp.com.br ou santin@uenp.edu.br

Submetido em: 7-12-2018

Aceito em: 29-1-2019 